CARPATHIAN JOURNAL OF FOOD SCIENCE AND TECHNOLOGY

journal home page:http://chimie-biologie.ubm.ro/carpathian_journal/index.html

\title{
CLASSIFICATION BY ARTIFICIAL NEURAL NETWORK FOR MUSHROOM COLOR CHANGING UNDER EFFECT UV-A IRRADIATION
}

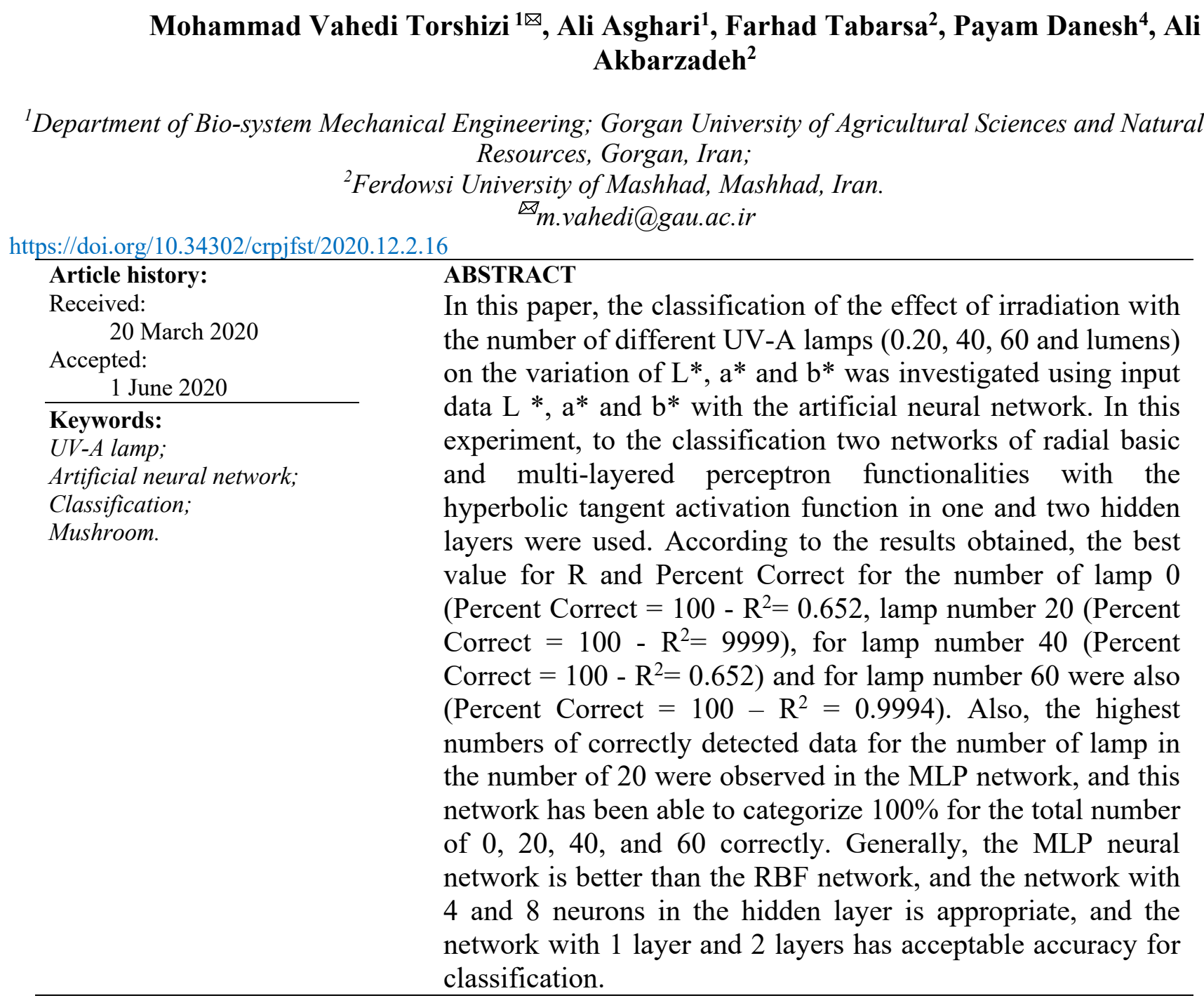

\section{Introduction}

Non-modern statistical methods for modeling difficult and nonlinear calculations are often unusable, especially if the relationship between output and measured characteristics of the model is not clear. One type of computation that is used to address the bugs of non-modern methods is intelligent predictive methods such as artificial neural networks. These types of systems have properties such as learning capability, generalizability, information dispersion, parallel processing, and robustness, use in pattern separation, grading, approximation of function, and correlation equation. Generally, wherever one needs to learn a linear or nonlinear mapping, it should be used. Artificial neural networks today play an important role in predicting process parameters as a powerful tool (Van Dam 2014; Johnsson et al., 2018). The most important advantage of artificial neural networks is that they do not require a basic model for linking 
incoming and outgoing data to predict different parameters to predict different parameters (Rahal et al., 2018). The other advantages of the neural networks, as compared to other intelligent systems, are the ability to learn them on a very small scale from the surrounding area and the ability to generalize this learning. In general, this method tries to establish a linear or nonlinear model between independent and dependent variables based on the inherent relationships between the data. Different types of artificial networks have been introduced, which are mainly used in applications such as classification, clustering, pattern recognition, and modeling, approximation of functions, control, estimation and optimization (Hertz., 2018). Other uses of the artificial neural network include the use of these networks by researchers in agricultural sciences to simulate parameters such as evapotranspiration (Chowdhary et al., 2010), evapotranspiration (Ashrafzadeh et al. 2018)، air temperature prediction (Rodrigues et al., 2018), solar radiation(Işık and Inallı 2018), flood prediction, and soil water retaining capability (Lykhovyd., 2018). Neural network models, unlike mathematical models, without the need to extract the relationship between parameters, are able to identify the relationship between them, and in this regard are considered as a very powerful tool in modeling. In this method, the relationship between the parameters in the stage of network education is introduced and in the next stage, it is act similar to the human brain, and with training, the neural network will be able to predict the process and the problems associated with extracting the relationship between the parameters are eliminated. Therefore, neural network models are often used in cases where the relationship between parameters is unknown or very difficult (Ghasemi et al., 2017). The most common neural networks, the type of multilayer perceptron that consists of the input layer, the hidden or middle layer, and the output layer (Alam et al., 2018). Classification is defined as a method in which each sample is in a predetermined class and, using a series of initial information, the samples are assigned to certain categories. The classification of large databases makes it possible to use a large amount of information to be assigned to several smaller, more consistent categories, in various modeling processes(Gonçalves et al., 2018). Fuzzy clustering and artificial neural network methods are among the algorithms used in the classification. Fuzzy clustering is a method that matches the fuzzy logic in which each dataset belongs to a group that is characterized by its membership grade (Moorthi et al., 2018). With the advent of computers in recent years, it has been possible to carry out in-house procedures on a large volume of data and the use of classification methods has been expanded. Classes can be divided into generic and advanced divisions. General categorization methods include the maximum probability and the minimum distance. Also, advanced classification, artificial neural networks, decision tree, backup vector machine, and object-oriented classification can be mentioned (Das et al., 2017). Barbero et al., (2006) examined the amount of ultraviolet radiation by two methods, one based on traditional statistical techniques and another artificial neural network, and acknowledged the high ability of artificial neural network (Barbero et al., 2006). Huang et al., (2017) studied the capability of ethyl hexalyl salicylate to absorb ultraviolet radiation by artificial neural network and found that this material has high economic potential (Huang et al., 2017). Luque et al., (2006) Used spectroscopy, ultraviolet ray, and pattern recognition techniques for differentiating and classifying wines, and the speed of analysis and review was Impressive (Luque et al., 2006) . Rahman et al., (2016) with the classification of fresh and non-fresh fish, based on the effect of ultraviolet radiation on the fish's eyes, obtained an appropriate assessment of fish's liveliness and shelf-life (Rahman et al., 2016). Due to the fact that mushrooms are air-sensitive products and have many color changes, so it is necessary to use different methods to investigation the prediction and classification of these products 
that the artificial neural network is one of the prediction methods. The aim of this paper is to classify the color change of the fungus in UVA irradiation, whether the neural network has the proper ability to classify the amount of UV radiation. Also, the sensitivity coefficient $\mathrm{L} *$, $\mathrm{b}^{*}$ and $\mathrm{a}^{*}$ is obtained using artificial neural network.

\section{Materials and methods}

\subsection{Sample preparation}

Samples from the mushroom Production Plant in Golestan province were freshly prepared and sent to the Laboratory of Biosystem Mechanics Department of the University of Agricultural Sciences and Natural Resources, and after washing with standard methods, the moisture content of mushroom was measured using oven (Figure 1). The moisture content of mushroom was $89.6 \pm$ $1.5 \%$ wet basis. After measuring the moisture content, samples were cut into slices with a thickness of $5 \mathrm{~mm}$ and placed after encoding in the cellophane (Polyolefin film). The encoded samples were placed in three groups of 20, 40 and 60 lamps, to be irradiated, and all experiments were carried out with three replications. Also, for color variation to be checked, control treatment with no irradiation on it was selected.

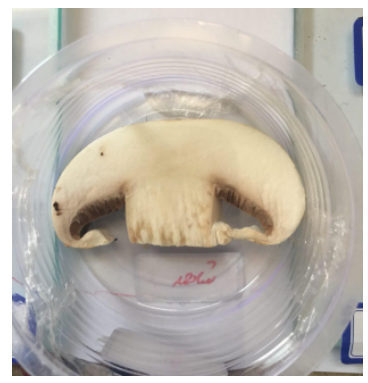

Figure 1. The mushroom samples placing method in into plate

\subsection{Irradiation of samples}

After preparing, the samples were exposed to UV, A, 20, 40 and 60 for 10, 20 and 30 minutes. The irradiation interval was $0.5 \mathrm{~cm}$ from the specimens, and in Figures 2 and 3 were showed how the lamps are illuminated and the distance and placement of the sample.
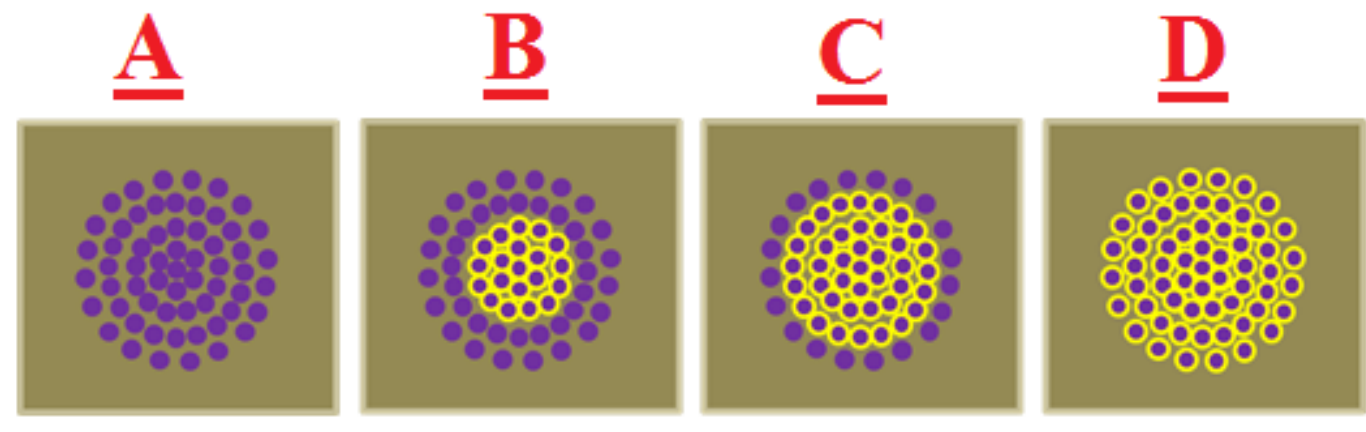

Figure 2. Arrange lamps method for irradiation - A: The total number lamps B: Twenty lamps C: Forty lamps D: Sixty lamps

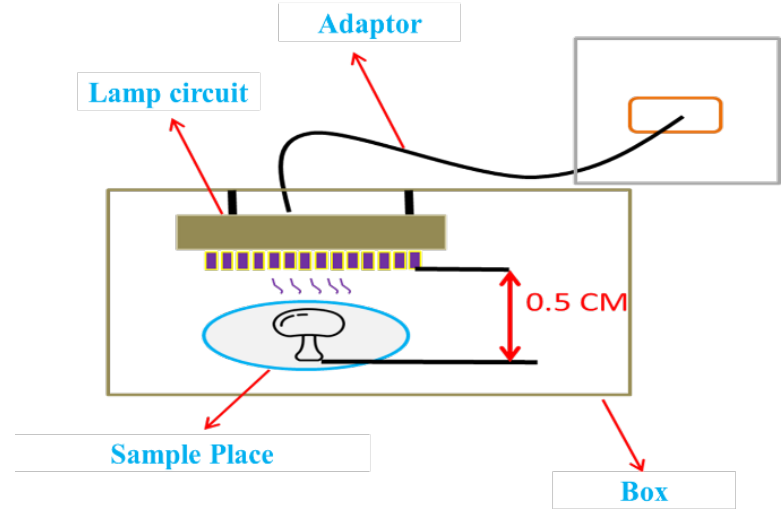


Figure 3. Sample place in box and irradiation UV-A

\subsection{Imaging samples}

All photos were taken before irradiation and then, after irradiation of each sample, photos were taken every one hour in 24 hours (in one day) for each specimen. Photography was done using the canon ixus 132hd camera and the camera was mounted Perpendicular to the sample product on the camera's location. The photography was taken in a closed box with the same exposure for all specimens to prevent different light exposure to the product.

\subsection{Color analysis}

In the analysis of color values, the values of $\mathrm{L}^{*}, \mathrm{a}^{*}$ and $\mathrm{b}^{*}$ were used and this is due to the independence of this analysis from the device and covers a wider range than RGB and CMYK. Image $J$ software was used to analyze images and obtain color values. First, it was done to improve the images and remove unnecessary components in the image for all pre-processing images. In the process of image processing, the general purpose at this stage is to identify features of the image that can be used for their intended use. The images were converted from RGB to $\mathrm{XYZ}$ and then to $\mathrm{L} *$, $a^{*}$ and $b^{*}$ using two steps. Using (Eq.1), which is the method used by San and colleagues, the images can be converted from the RGB color space to the $X Y Z$ color space. Also using (Eq. 2 to 4 ), the $X Y Z$ images can be converted to $L$ $*$, a* and $b^{*}$ in the next step.

$$
\left[\begin{array}{l}
\hat{X} \\
\hat{Y} \\
\hat{Z}
\end{array}\right]=\left(\begin{array}{lll}
0412456 & 0.257580 & 0.180423 \\
0212671 & 0.715160 & 0.072169 \\
0.019334 & 0.119194 & 0.950227
\end{array}\right)\left[\begin{array}{l}
\hat{R} \\
\hat{G} \\
\hat{B}
\end{array}\right]
$$

$$
\widehat{L}=\left[\begin{array}{c}
116 \times\left(\frac{\hat{Y}}{Y^{\prime}}\right)^{\frac{1}{3}}-16 \\
903.3 \times\left(\frac{\hat{Y}}{Y^{\prime}}\right) E L S E
\end{array}\right\rfloor(2) \hat{a}=500 \times\left\lfloor\left(\frac{\hat{X}}{X^{\prime}}\right)^{\frac{1}{3}}-\left(\frac{\hat{Y}}{Y^{\prime}}\right)^{\frac{1}{3}}\right\rfloor
$$

$$
\hat{a}=500 \times\left\lfloor\left(\frac{\widehat{X}}{X^{\prime}}\right)^{\frac{1}{3}}-\left(\frac{\widehat{Y}}{Y^{\prime}}\right)^{\frac{1}{3}}\right\rfloor
$$

$$
\hat{b}=200 \times\left\lfloor\left(\frac{\hat{z}}{Z^{\prime}}\right)^{\frac{1}{3}}-\left(\frac{\hat{Y}}{Y^{\prime}}\right)^{\frac{1}{3}}\right\rfloor
$$

Where $X^{\prime}$, $Y^{\prime}$ and $Z$ 'are $X Y Z$ values for the 65 standard.

$$
\left[\begin{array}{l}
\hat{X} \\
\hat{Y} \\
\hat{Z}
\end{array}\right]=\left(\begin{array}{c}
95.047 \\
100 \\
108.883
\end{array}\right)
$$

\subsection{Artificial Neural Network Modelling}

In this research, a multi-layered perceptron (MLP) and a radial base function (RBF) neural network were used to classify UV-A lamps. For these networks, 1 and 2 layers were hidden and 4 and 8 neurons were selected, the selected networks were separately trained and formed and analyzed using NeuroSolution6 software. The hyperbolic tangent activation function of (Table 1).Which is most used for processing, was selected and used in both of input and output. In this research, the Levenberg-Markott optimization method was used for network training. The values of $\mathrm{L} *, \mathrm{a}^{*}$ and $\mathrm{b}^{*}$ were selected as inputs for the classification and number of bulbs $(0.20,40$ and 60$)$ as the output of the networks. $70 \%$ of the data for training and $15 \%$ for the test, and $15 \%$ for the evaluation of the network were used. In the formation of these networks, 5 repetitions were selected for simulating artificial neural network data to achieve the minimum error rate and maximum network stability, averaging 5,000 Epoch to simulate data by neural network. Error Estimating Algorithm in Networks the compilation was performed using an error-back propagation algorithm. For estimating the network, two factors of the coefficient of explanation $\left(\mathrm{R}^{2}\right)$ and root mean square error were used. The correlation coefficient determines the correlation between the output data of the neural network and the observed data and is calculated from (Eq.6), whose idea 
value is equal to 1 .The mean square error defines the difference between the predicted data and the actual data and its root is calculated from (Eq.9). The goal of a good network is to reduce this error to the lowest value, and its appropriate value is zero.

Table 1. Neural Network Relationships

\begin{tabular}{|c|c|c|}
\hline Formula & $\begin{array}{c}\text { Formula } \\
\text { Number }\end{array}$ & Reference \\
\hline $\mathrm{Tanh}=\frac{e^{x}-e^{-x}}{e^{x}+e^{-x}}$ & $\mathbf{( 6 )}$ & (Soleimanzadeh et al. 2015)(Kariman et al. 2019) \\
\hline $\mathrm{R}^{2}=1-\frac{\sum_{i=1}^{n}\left(P_{i}-O_{i}\right)^{2}}{\left(P_{i}-O\right)^{2}}$ & $\mathbf{( 7 )}$ & (Azadbakht et al. 2016;Azadbakht et al. 2018a) \\
\hline $\mathrm{r}=\sqrt{1-\frac{\sum_{i=1}^{n}\left(P_{i}-O_{i}\right)^{2}}{\left(P_{i}-O\right)^{2}}}$ & $\mathbf{( 8 )}$ & (Azadbakht et al.2019) \\
\hline $\mathrm{RMSE}^{1}=\sqrt{\sum_{i=1}^{n} \frac{\left(P_{i}-O_{i}\right)^{2}}{n}}$ & $\mathbf{( 9 )}$ & $\begin{array}{c}\text { (Khoshnevisan, Sh. Rafiee, M. Omid 2013)(Azadbakht } \\
\text { et al.2018b) }\end{array}$ \\
\hline $\mathrm{MAE}^{2}=\frac{\sum_{i=1}^{n}\left|P_{i}-O_{i}\right|}{n}$ & $\mathbf{( 1 0 )}$ & (Azadbakht et al. 2017) \\
\hline
\end{tabular}

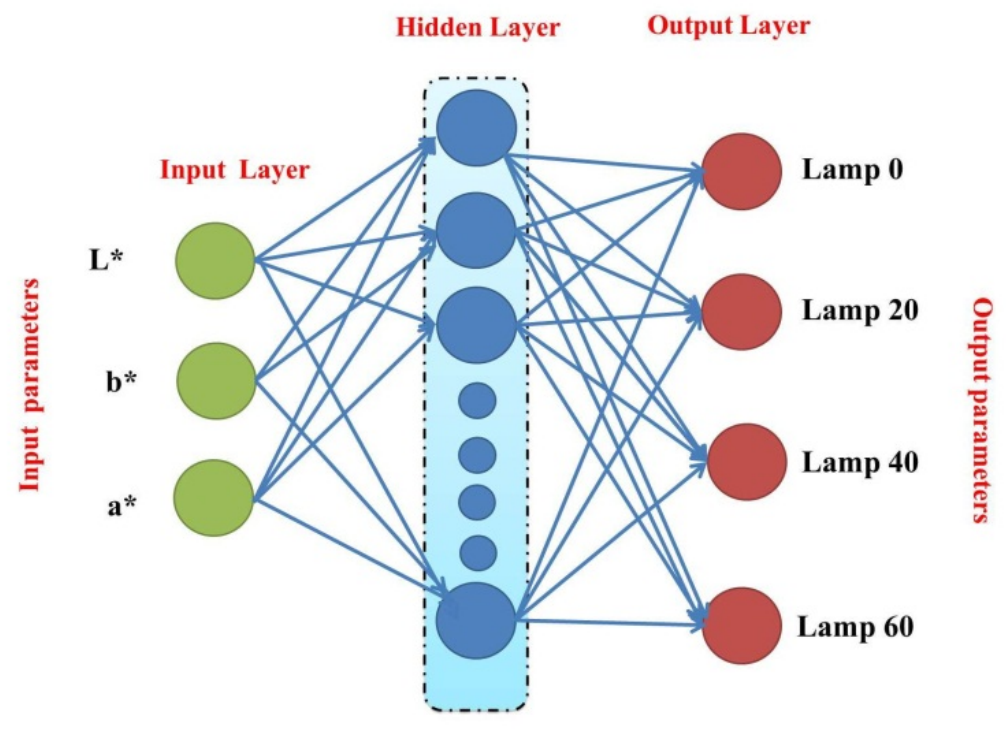

Figure 4. ANN schematic

\footnotetext{
${ }^{1}$ Root mean squared error
}

${ }^{2}$ Mean Absolute Error 


\section{Results and discussions}

Table 2 shows the RMSE, MAE, $\mathrm{R}^{2}$ and Percent Correct values. Accordingly, the best values for the MAE, $\mathrm{R}^{2}$ and Percent Correct in the MLP network with 4 neurons with two layers were hidden. The best values for the number of lamps are 60 RMSE Train $=9.49 \times 10^{-5}$, MAE Train $=7 \times 10^{5}, \mathrm{R}^{2}$ Train $=0.99999998$, Percent Correct Train $=100$ and for the number of bulbs, the best 40 values of the RMSE Train $=8.37 \times 10^{-5}$, MAE Train $=5.6 \times 10^{-5}, \quad \mathrm{R}^{2} \quad$ Train $=0.99999998$, Percent Correct Train $=100$ For the number of lamps 20, the best values are RMSE Train $=6.32 \times 10^{-5}, \quad$ MAE Train $=4 \times 10^{-5}, \quad \mathrm{R}^{2}$ Train $=0.99999998$, Percent Correct Train $=100$ and finally for the number 0 bulbs, The best values were, RMSE ${ }_{\text {Train }}=2.24 \times 10^{-5}$, MAE Train $^{2}=1 \times 10^{-5}$, $\mathrm{R}^{2}$ Train $=0.99999998$, Percent Correct Train $=100$. According to the results obtained, the best value for $\mathrm{R}^{2}$ and Percent Correct for the number of bulbs 0 (Percent Correct $=100-\mathrm{R}^{2}=0.652$, lamp 20 (Percent Correct $\left.=100-\mathrm{R}^{2}=9999\right)$, For lamp number 40 (Percent Correct $=100-$ $\left.\mathrm{R}^{2}=0.652\right)$ and for the number of bulbs, 60 were also (Percent Correct $=100-\mathrm{R}^{2}=$
0.9994). Also, the highest numbers of correctly detected data for the number of lamp in the number of 20 were observed in the MLP network, and this network has been able to categorize $100 \%$ for the total number of 0.20 , 40 , and 60 correctly. Also according to the results obtained when using the MLP network, the accuracy and predictability of the network were greater than the RBF network. Also, the closer RSME is to zero, the better the network performance, which is less than RBF in MLP networks, which means the accuracy of these networks are higher. According to the results, it can be stated that at a time when 4 neurons were used for the MLP network in hidden layers in a network with two hidden layers, they obtained better values than $\mathrm{R}^{2}$, RMSE, and Percent Correct and when 8 neurons are used in hidden layers, a hidden double-layer network has been able to show better values and for the RBF network it's exactly the opposite of the MLP network. In general, it can be argued that the MLP network has been able to display better $\mathrm{R}^{2}, \mathrm{RMSE}$, and Percent Correct values for

classification

Table 2. Error values in predicting experimental data using optimal artificial neural network

\begin{tabular}{|c|c|c|c|c|c|c|c|c|c|c|}
\hline \multirow{2}{*}{ 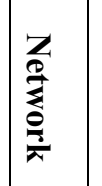 } & \multirow{2}{*}{ 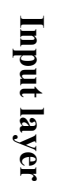 } & \multirow{2}{*}{$\begin{array}{l}\text { 离 } \\
\text { 壭志 }\end{array}$} & \multicolumn{2}{|c|}{ RMSE } & \multicolumn{2}{|c|}{ MAE } & \multicolumn{2}{|c|}{$\mathbf{R}^{2}$} & \multicolumn{2}{|c|}{ Percent Correct } \\
\hline & & & Train & Test & Train & Test & Train & Test & Train & Test \\
\hline \multirow{8}{*}{ 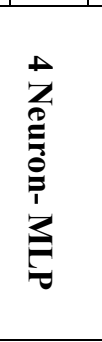 } & \multirow{4}{*}{1} & 60 & 0.024495 & 0.667083 & 0.0147 & 0.436 & 0.9986 & 0.386 & 100 & 33.333 \\
\hline & & 40 & 0.03 & 0.667832 & 0.0206 & 0.433 & 0.9988 & 0.2369 & 100 & 55.33 \\
\hline & & 20 & 0.03873 & 0.044721 & 0.0289 & 0.035 & 0.9992 & 0.999 & 100 & 100 \\
\hline & & $\mathbf{0}$ & 0 & 0.004472 & 0.0045 & 0.004 & 0.9996 & 1.000 & 100 & 100 \\
\hline & \multirow{4}{*}{2} & 60 & 9.49E-05 & 0.447258 & $7 \mathrm{E}-05$ & & 0.99999998 & 0.99693 & 100 & 83.66 \\
\hline & & 40 & $8.37 \mathrm{E}-05$ & 0.632487 & $6 \mathrm{E}-05$ & 0.20003 & 0.99999998 & -0.57344 & 100 & 0 \\
\hline & & 20 & $6.32 \mathrm{E}-05$ & 0.447225 & $4 \mathrm{E}-05$ & 0.40004 & 0.999999989 & 0.66666 & 100 & 100 \\
\hline & & $\mathbf{0}$ & $2.24 \mathrm{E}-05$ & 0.4036 & $1 \mathrm{E}-05$ & 0.20002 & 0.999999998 & 1 & 100 & 100 \\
\hline \multirow{8}{*}{$\begin{array}{l}\infty \\
Z \\
0 \\
\Xi \\
0 \\
\vdots \\
1 \\
1 \\
3 \\
0\end{array}$} & \multirow{4}{*}{1} & 60 & 0.004472 & 0.449555 & $2.2 \mathrm{E}-03$ & 0.2256 & 0.9999578 & 0.615 & 100 & 100 \\
\hline & & 40 & 0.004583 & 0.449555 & $2.4 \mathrm{E}-03$ & 0.2277 & 0.9999595 & 0.652 & 100 & 66.667 \\
\hline & & 20 & 0.000933 & 0.155563 & $7.0 \mathrm{E}-04$ & 0.0738 & 0.9999981 & 0.935 & 100 & 100 \\
\hline & & $\mathbf{0}$ & 0.000616 & 0.000316 & 4.4E-04 & 0.0002 & 0.9999998 & 0.9036 & 100 & 50.33 \\
\hline & \multirow{4}{*}{2} & 60 & 0.00945 & 0.443847 & $6.93 \mathrm{E}-03$ & 0.210 & 0.999950 & 0.631 & 100 & 50 \\
\hline & & 40 & 0.009429 & 0.441588 & 7.04E-03 & 0.216 & 0.99989 & 0.89 & 100 & 50 \\
\hline & & 20 & 0.003606 & 0.094868 & $3.12 \mathrm{E}-03$ & 0.051 & 0.99999 & 0.976 & 100 & 100 \\
\hline & & $\mathbf{0}$ & 0.002938 & 0.070711 & $2.30 \mathrm{E}-03$ & 0.040 & 0.99998 & 0.991 & 100 & 100 \\
\hline \multirow{3}{*}{ 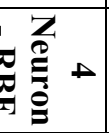 } & \multirow{3}{*}{1} & 60 & 0.016125 & 0.028284 & 0.01226 & 0.0222 & 0.99949 & 0.9994 & 100 & 100 \\
\hline & & 40 & 0.013038 & 0.024495 & 0.00970 & 0.0194 & 0.99967 & 0 & 100 & 50.33 \\
\hline & & 20 & 0.009487 & 0.022361 & 0.00766 & 0.0178 & 0.99983 & 0.9997 & 100 & 100 \\
\hline
\end{tabular}


Vahedi Torshizi et al./Carpathian Journal of Food Science and Technology, 2020, 12(2), 152-162

\begin{tabular}{|c|c|c|c|c|c|c|c|c|c|c|}
\hline & & $\mathbf{0}$ & 0.008944 & 0.01 & 0.00646 & 0.0070 & 0.99975 & 0.9999 & 100 & 100 \\
\hline & \multirow{4}{*}{2} & 60 & 0.5 & 1.28841 & 0.5 & 0.3999 & 0.0989799 & 0.400005 & 100 & 0.166 \\
\hline & & 40 & 0.5 & 1.28841 & 0.5 & 0.3999 & 0.0984165 & 0.400006 & 0 & 0.166 \\
\hline & & 20 & 0.5 & 1.32365 & 0.5 & $7.82 \mathrm{E}-12$ & 0.0978989 & $2.35 \mathrm{E}-06$ & 0 & 3.36 \\
\hline & & $\mathbf{0}$ & 0.5 & 1.296399 & 0.5 & $1.89 \mathrm{E}-12$ & 0.0989369 & $1.08 \mathrm{E}-06$ & 0 & 0989 \\
\hline \multirow{8}{*}{ 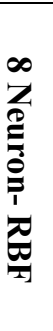 } & \multirow{4}{*}{1} & 60 & 0.6245 & 0.465403 & 0.404 & 0.2482 & -0.399 & $\begin{array}{l}-0.3907 \\
\end{array}$ & 0 & 0 \\
\hline & & 40 & 0.474342 & 0.404846 & 0.325 & 0.2663 & 0.608 & 0.6830 & 100 & 100 \\
\hline & & 20 & 0.451664 & 0.484045 & 0.216 & 0.2731 & 0.567 & 0.5641 & 100 & 100 \\
\hline & & $\mathbf{0}$ & 0.337639 & 0.356371 & 0.211 & 0.2300 & 0.734 & 0.6679 & 0 & 0 \\
\hline & \multirow{4}{*}{2} & 60 & 0.042426 & 0.595651 & 0.0224 & 0.3109 & 0.9971 & 0.2949 & 100 & 50 \\
\hline & & 40 & 0.022361 & 0.641716 & 0.0150 & 0.4134 & 0.9990 & -0.2721 & 100 & 0 \\
\hline & & 20 & 0.014142 & 0.336749 & 0.0125 & 0.0449 & 0.9995 & 0.8912 & 100 & 100 \\
\hline & & $\mathbf{0}$ & 0.014142 & 0.144914 & 0.0101 & 0.0009 & 0.9992 & 0.9993 & 100 & 100 \\
\hline
\end{tabular}

Mean square error (MSE) - Root mean square error (RMSE) - Mean absolute error (MAE) - $\mathrm{R}^{2}$ : Coefficient of determination

In Table 3 the results of classification are shown using the neural network for the number of $60,40,20$ and 0 lamps. According to the results, it can be stated that in the MLP network all data is correctly predicted.

Table 3. Classification values for RBF and MLP networks

\begin{tabular}{|c|c|c|c|c|c|c|c|c|c|c|}
\hline \multirow{3}{*}{$\frac{Z}{2} \frac{Z}{2}$} & \multirow{3}{*}{ 昰 } & \multirow{3}{*}{ 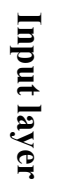 } & \multicolumn{8}{|c|}{ Lamp number } \\
\hline & & & \multicolumn{2}{|c|}{$\mathbf{0}$} & \multicolumn{2}{|c|}{20} & \multicolumn{2}{|c|}{ है } & \multicolumn{2}{|c|}{60} \\
\hline & & & Train & Test & Train & Test & Train & Test & Train & Test \\
\hline \multirow{8}{*}{ 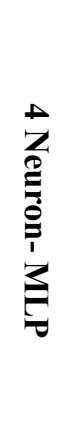 } & 60 & 1 & 0 & 0 & 0 & 0 & 0 & 0 & 60 & 1 \\
\hline & & 2 & 0 & 0 & 0 & 0 & 0 & 1 & 8 & 0 \\
\hline & 40 & 1 & 0 & 0 & 0 & 0 & 8 & 0 & 40 & 2 \\
\hline & & 2 & 0 & 0 & 0 & 0 & 5 & 0 & 0 & 0 \\
\hline & 20 & 1 & 0 & 0 & 8 & 1 & 0 & 0 & 20 & 0 \\
\hline & & 2 & 0 & 0 & 5 & 2 & 0 & 1 & 0 & 0 \\
\hline & 0 & 1 & 1 & 1 & 0 & 0 & 0 & 0 & $\mathbf{0}$ & 0 \\
\hline & & 2 & 4 & 1 & 0 & 0 & 0 & 0 & 0 & 0 \\
\hline \multirow{8}{*}{ 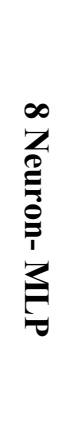 } & 60 & 1 & 0 & 0 & 0 & 0 & 0 & 1 & 60 & 1 \\
\hline & & 2 & 0 & 0 & 0 & 0 & 0 & 0 & 6 & 1 \\
\hline & 40 & 1 & 0 & 0 & 0 & 0 & 6 & 2 & 40 & 0 \\
\hline & & 2 & 0 & 0 & 0 & 0 & 6 & 0 & 0 & 1 \\
\hline & 20 & 1 & 0 & 0 & 5 & 1 & 0 & 0 & 20 & 0 \\
\hline & & 2 & 0 & 0 & 8 & 1 & 0 & 0 & 0 & 0 \\
\hline & 0 & 1 & 5 & 0 & 0 & 0 & 0 & 0 & $\mathbf{0}$ & 0 \\
\hline & & 2 & 2 & 2 & 0 & 0 & 0 & 0 & 0 & 0 \\
\hline \multirow{5}{*}{ 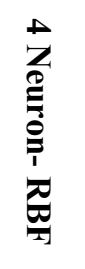 } & 60 & 1 & 0 & 0 & 0 & 0 & 0 & 0 & 60 & 2 \\
\hline & & 2 & 5 & 0 & 7 & 0 & 5 & 1 & 5 & 2 \\
\hline & 40 & 1 & 0 & 0 & 0 & 0 & 7 & 0 & 40 & 0 \\
\hline & & 2 & 0 & 0 & 0 & 0 & 0 & 1 & 0 & 1 \\
\hline & 20 & 1 & 0 & 0 & 6 & 2 & 0 & 0 & 20 & 0 \\
\hline
\end{tabular}




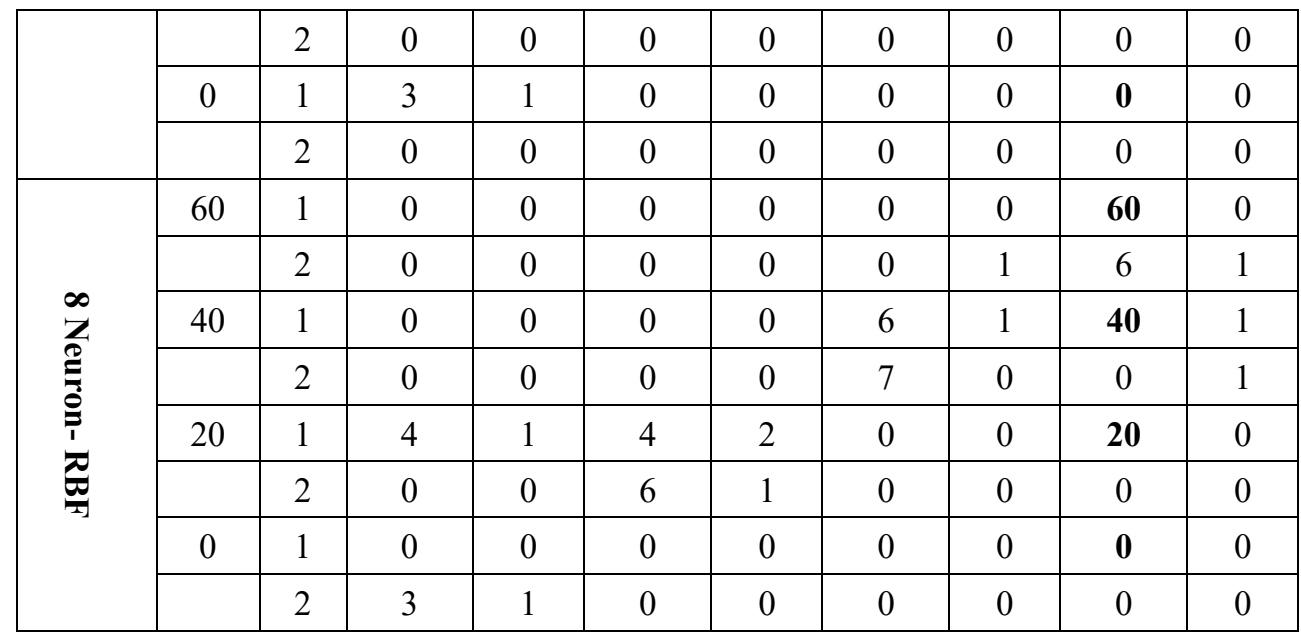

It is possible to choose the best network using RMSE and $\mathrm{R}^{2}$, and for the prediction percentage, no difference between the 4 and 8 neurons in the hidden layers of the 1 layer and 2. This demonstrates the very good ability of this network to predict and classify, and for the neural network RBF network trained with 4 neurons and hidden layers, and 8 neurons and two hidden layers, has been able to categorize $100 \%$ of the data. Table 4 shows the results of learning the neural network. According to the results shown in the Table, it can be stated that the fastest network is RBF network with 8 neurons and one hidden layer and for Cross Validation, the fastest network is RBF with 4 neurons and one hidden layer but according to the results, the $\mathrm{R}^{2}$ and RMSE were not good enough. Also Azadbakht et al., (2020) reported that RBF neural network is faster than MLP neural networks.

Table 4. Some of the best MLP and RBF neural network topologies to predict test value

\begin{tabular}{|c|c|c|c|c|}
\hline & Input layer & Cross Validation & Training & \\
\hline \multirow{4}{*}{ 蛋 } & \multirow{2}{*}{1} & 4 & 2 & RUN \\
\hline & & 4999 & 66 & ЕРОСН \\
\hline & \multirow{2}{*}{2} & 4 & 1 & RUN \\
\hline & & 199 & 2020 & ЕРОСН \\
\hline \multirow{4}{*}{ 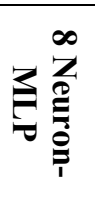 } & \multirow{2}{*}{1} & 5 & 1 & RUN \\
\hline & & 48 & 2017 & ЕРОСН \\
\hline & \multirow{2}{*}{2} & 3 & 1 & RUN \\
\hline & & 61 & 2022 & ЕРОСН \\
\hline \multirow{4}{*}{ 苗 } & \multirow{2}{*}{1} & 1 & 1 & RUN \\
\hline & & 15 & 2014 & ЕРОСН \\
\hline & \multirow{2}{*}{2} & 1 & 1 & RUN \\
\hline & & 23 & 299 & ЕРОСН \\
\hline \multirow{4}{*}{ 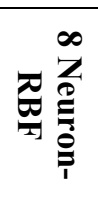 } & \multirow{2}{*}{1} & 5 & 1 & RUN \\
\hline & & 7 & 117 & ЕРОСН \\
\hline & \multirow{2}{*}{2} & 1 & 1 & RUN \\
\hline & & 18 & 2018 & ЕРОСН \\
\hline
\end{tabular}


The sensitivity coefficient for $\mathrm{L} *$, a* are shown in (Figures 5 and 6), and the sensitivity coefficient $b^{*}$ for both the MLP and RBF with the number of neurons and various layers has been zero. For L *, the highest color-sensitivity coefficient was observed in the number of bulbs 20 and in the MLP network, and for the number of bulbs 0 and 60 , the coefficient of sensitivity was lower than $\mathrm{L} *$.In the number of lamps 20, 40 and 60, the highest sensitivity was found in the MLP network and the network with 4 neurons in the hidden layer and one hidden layer. For the $a^{*}$ value, a very low sensitivity coefficient for the number of bulbs has been obtained and the number of lamps 20 with both RBF and MLP networks in both Neuron 4 and 8 neurons, and 1 and 2 layers of the hidden layer were able to obtain a relatively high sensitivity coefficient and the sensitivity coefficient has decreased as the number of lamps has increased, and the sensitivity factor of 60 bulbs has been less than 40 lamps

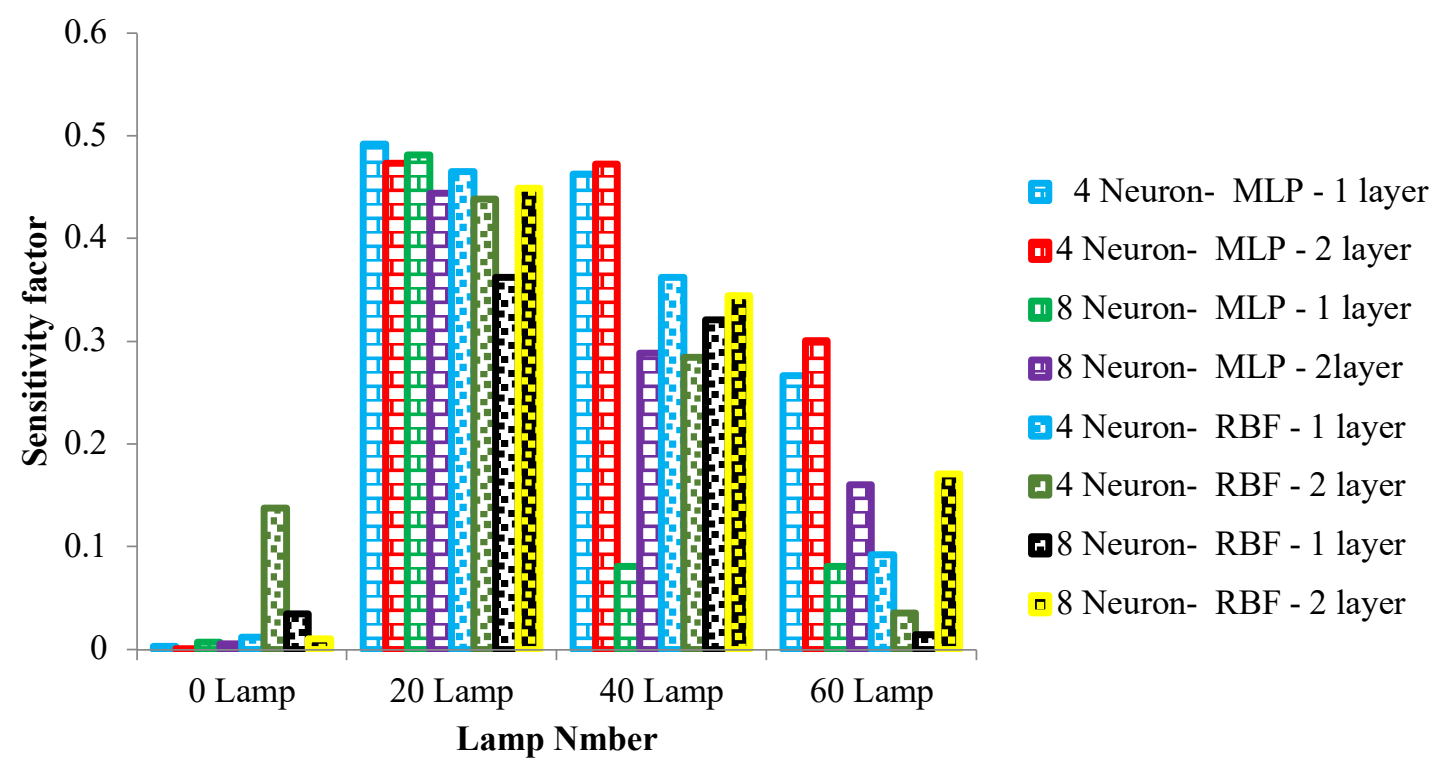

Figure 5. The sensitivity coefficient $\mathrm{L} *$ in number of different lamps

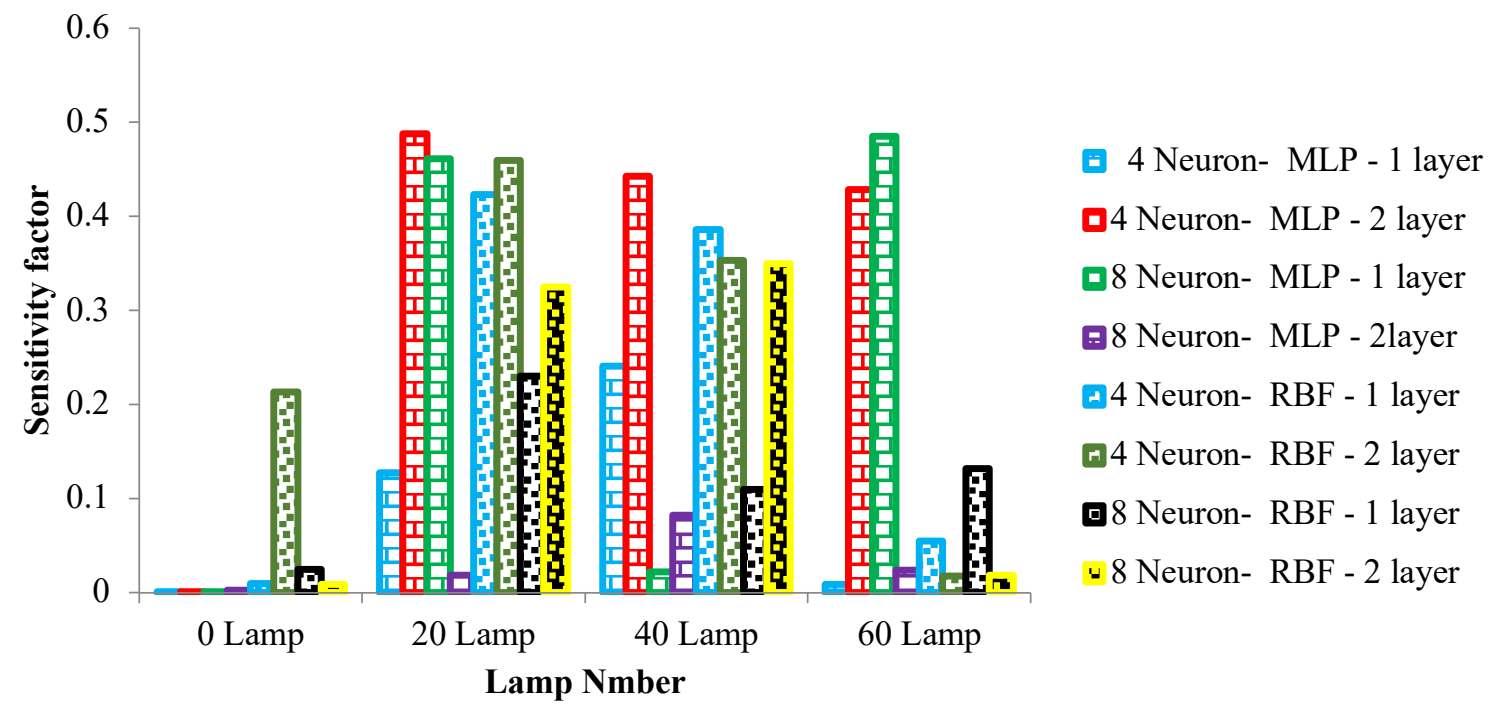

Figure 6. The sensitivity coefficient a* in number of different lamps 


\section{Conclusions}

According to the results of the network, the MLP network classification to categorize all the data accurately $(100 \%)$ for the training, and the network have an appropriate R-value, and all $\mathrm{R}^{2}$ for networks with 4,8 , and 1 neuron And 2 hidden layers above 0.99 , which indicates the high ability of this network. Also, the network with 2 hidden layers and 4 neurons in the hidden layer had the least amount of MSE, and for a network with 8 neurons, the MSE was less than the MLP network with 4 neurons and 1 hidden layer, as well as the RBF network. For the sensitivity coefficient, the results also showed that for $\mathrm{L}^{*}$, the number of lamps were 20 , the highest was the sensitivity coefficient and was the lowest in 0 lamps. According to the results of the MLP network with 4 neurons in the hidden layer in the 1st and 2nd layer, the highest sensitivity coefficient was found for the number of 20, 40 and 60 lamps. The sensitivity coefficient of 0 bulbs with the RBF network had the highest sensitivity coefficient and in total it can be argued that the MLP neural network efficiency was better for the color change classification than the RBF network.

\section{References}

Alam, M.A., Saha, C.K., Alam, M.M., Ashraf, M.A., Bala, B.K. Harvey, J. (2018). Neural network modeling of drying of rice in BAU-STR dryer. Heat and Mass Transfer, 54(11), pp.3297-3305.

Ashrafzadeh, A., Malik, A., Jothiprakash, V., Ghorbani, M.A. Biazar, S.M. (2018). Estimation of daily pan evaporation using neural networks and meta-heuristic approaches. ISH Journal of Hydraulic Engineering, pp.1-9.

Azadbakht, M., Aghili, H., Ziaratban, A., Vahedi Torshizi, M. (2017). Application of artificial neural network method to exergy and energy analyses of fluidized bed dryer for potato cubes. Energy 120:947-958.

Azadbakht, M., Vahedi Torshizi, M., Noshad, F., Rokhbin, A. (2018a). Application of artificial neural network method for prediction of osmotic pretreatment based on the energy and exergy analyses in microwave drying of orange slices. Energy 165:836-845.

Azadbakht M, Vahedi Torshizi, M. Chajarjazi, E., Ziaratban, A. (2016). Application of Artificial Neural Network (ANN) in predicting mechanical properties of canola stem under shear loading. Agricultural Engineering International: CIGR Journal, 18, 413-424.

Azadbakht, M., Vahedi Torshizi, M., Aghili, H., Ziaratban, A. (2018b). Application Of Artificial Neural Network (Ann) In Drying Kinetics Analysis For Potato Cubes. Carpathian Journal of Food Science \& Technology, 10(2), 96-106.

Barbero, F.J., Lopez, G. Batlles, F.J. (2006). Determination of daily solar ultraviolet radiation using statistical models and artificial neural networks. Annales Geophysicae,24, 2105-2114.

Chowdhary, A., Shrivastava, R.K. (2010). Reference crop evapotranspiration estimation using artificial neural networks. International Journal of Engineering, Science and Technology, 2(9), pp.42054212.

Das, S., Routray, A. and Deb, A.K. (2017). December. Hyperspectral unmixing by nuclear norm difference maximization based dictionary pruning. In 2017 14th IEEE India Council International Conference (INDICON) (pp. 1-5). IEEE.

Ghasemi, N., Aghayari, R. and Maddah, H.( 2018). Designing an artificial neural network using radial basis function to model exergetic efficiency of nanofluids in mini double pipe heat exchanger. Heat and Mass Transfer, 54(6), 1707-1719.

Gonçalves, M.F., Blanco, C.J.C., dos Santos, V.C. dos Santos Oliveira, L.L. (2018). Homogenous regions and rainfall 
probability models considering El Niño and La Niña in the State of Pará in the Amazon. Acta Scientiarum. Technology, 40, 3774237742.

Hertz, J.A. (2018) Introduction To The Theory Of Neural Computation. CRP press.

Huang, S.M., Hung, T.H., Liu, Y.C., Kuo, C.H., Shieh, C.J.(2017). Green synthesis of ultraviolet absorber 2-ethylhexyl salicylate: Experimental design and artificial neural network modeling. Catalysts, 7(11), 342.

Iş1k, E., Inallı, M.(2018). Artificial neural networks and adaptive neuro-fuzzy inference systems approaches to forecast the meteorological data for HVAC: The case of cities for Turkey. Energy, 154, pp.7-16.

Johnsson, O.(2018). Predicting Stock Index Volatility Using Artificial Neural Networks: An empirical study of the OMXS30, FTSE100 \& S\&P/ASX200. Search Results. Lund University publication.

Kariman, M., Tabarsa, F., Zamani, S., Kashi, P. A., \& Vahedi Torshizi, M. (2019). Classification Of The Energy And Exergy Of Microwave Dryers In Drying Kiwi Using Artificial Neural Networks. Carpathian Journal of Food Science \& Technology, 11(2),29-45.

Khoshnevisan, B., Rafiee, S., Omid, M. and Yousefi, M. (2013). Prediction of environmental indices of Iran wheat production using artificial neural networks. International Journal of Energy \& Environment, 4(2).

Likhovid, P.(2018). Prediction of sweet corn yield depending on cultivation technology parameters by using linear regression and artificial neural network methods. Biosystems Diversity, 26(1), 11-15.

Moorthi, P.V.P., Singh, A.P., Agnivesh, P.( 2018). Regulation of water resources systems using fuzzy logic: a case study of Amaravathi dam. Applied Water Science, 8(5), 132.

Rahal, N.S., Alhumairi, B.A.J.(2019). Modelling of soil cation exchange capacity for some soils of east gharaf lands from mid-Mesopotamian plain (Wasit province/Iraq). International journal of environmental science and technology, 16(7), 3183-3192.

Rahman, A., Kondo, N., Ogawa, Y., Suzuki, T., Shirataki, Y. and Wakita, Y.(2016). Classification of fresh and spoiled Japanese dace (Tribolodon hakonensis) fish using ultraviolet-visible spectra of eye fluid with multivariate analysis. Engineering in agriculture, environment and food, 9(1), 64-69.

Rodrigues, E., Gomes, Á., Gaspar, A.R., Antunes, C.H.(2018). Estimation of renewable energy and built environmentrelated variables using neural networks-A review. Renewable and Sustainable Energy Reviews, 94,959-988.

Soleimanzadeh, B., Hemati, L., Yolmeh, M., Salehi, F.(2015). GA-ANN and ANFIS Models and $\mathrm{S}$ almonella Enteritidis Inactivation by Ultrasound. Journal of Food Safety, 35(2), 220-226.

Vahedi Torshizi, M., Azadbakht, M. (2020). Study on Firmness and texture changes of pear fruit when loading different forces and stored at different periods using artificial neural network. Iranian Food Science and Technology Research Journal, 15(6),113132.

Van Dam, R.L.(2014). Calibration functions for estimating soil moisture from GPR dielectric constant measurements. Communications in soil science and plant analysis, 45(3), pp.392-413. 